\title{
SUSTAINABLE DEVELOPMENT GOALS IN VIETNAM EDUCATION AND FUTURE SOLUTION
}

\author{
Associate Professor Le Khanh Tuan, PhD. \\ Saigon University, Vietnam
}

DOI: 10.46609/IJSSER.2020.v05i12.003 URL: https://doi.org/10.46609/IJSSER.2020.v05i12.003

\begin{abstract}
Implementation of the 2030 Agenda for Sustainable Development. In 2018, the Global Action Week for Education was launched by the United Nation sunder the theme "Accountability in sustainable development goal for education and active citizen participation". This article reviews difficulties and challenges faced by Vietnam in the implementation of sustainable development goal for education by 2025 and orientation to 2030; hence, requesting management measures in order to improve accountability and aim to a leave-no-one-behind education.
\end{abstract}

Keywords: Solutions, accountability, education, leave no one behind.

\section{Introduction}

In November 2015, the United Nations General Assembly ratified "the 2030 Agenda for Sustainable Development: Transforming our world". A plan of action for people, planet and prosperity is launched with 17 sustainable development goals (SDGs - Sustainable Development Goals), 169 associated targets and 230monitoring indicators, that encompass economic, social and environmental dimensions. In which, Goal 4 (SDG4) aims to "ensure inclusive and equitable quality education and promote lifelong learning opportunities for all”, comprising 7 targets and 11 goals.

In order to ensure the SDG4 pledge implementation from all governments, international organizations and stakeholders around the world, Global Action Week for Education is organized by the United Nations annually; in which the 2018 theme was entitled "Accountability for SDG4 through Citizen Participation". In response to the United Nations' recommendation, Vietnam has taken some actions to promote the implementation, in which searching for accountability for tracking and supervising the development of the leave-no-one-behind education. 
International Journal of Social Science and Economic Research

ISSN: 2455-8834

Volume:05, Issue:12 "December 2020"

This article introduces the summary of Government of Vietnam pledges including targets and means of implementation of sustainable development goals for education.

\section{Research Content}

\subsection{Government of Vietnam pledges:}

Since 2012, at the United Nations Conference on Sustainable Development hosted in Rio de Janeiro, Brazil, Vietnamese government has claimed "Sustainable development is a global trend that everyone is striving toward. It has also become viewpoints, guidelines and policies of the Communist Party of Vietnam; and is clearly shown in strategic planning for socio-economic development as well as other regional sectors in Vietnam".

Particularly in the field of education, in 2015 in Korea, along with other 160 countries, Vietnam ratified the "In cheon Declaration for Education 2030" with a 20-point framework of action, striving toward a new vision for education and pledging to implement a general agenda.

Based on the international pledges of the SDGs, on October $5^{\text {th }}, 2017$, the Prime Minister signed Decision No. 622 / QD-TTg on promulgating the National Action Plan to implement the 2030 Agenda for Sustainable Development, containing:

_ Setting out 17 goals for our socio-economic development, including a global education goal (SDG 4), which is to "ensure inclusive and equitable quality education and promote lifelong learning opportunities for all by 2030 ”.

_ Setting out 115 specific targets, in which SDG4 has 8 specific goals.

_ Assigning to ministries, branches and promulgating action plan in order to implement assigned goals and tasks, build a set of statistical indicators and a database system for monitoring and evaluation.

\subsection{Education implementation plan}

Follow the Prime Minister's Decision No. 622, on June 26 ${ }^{\text {th }}$, 2017, Minister of Education and Training signed Decision No. 2161/QĐ-DHQGHN to promulgate an action plan of implementing sustainable development goal for education by 2025 and orientation to 2030 (KH2161).

KH2161 includes 6 general targets, 33 specific goals, 45 monitoring indicators and is divided into 3 periods: by 2020, by 2025 and vision to 2030. Six general targets comprise: increasing 
International Journal of Social Science and Economic Research

ISSN: 2455-8834

Volume:05, Issue:12 "December 2020"

access to education at all levels (7 specific goals); encouraging high-quality child care and education (4 specific goals); developing high-quality education in college and university (5 specific goals); ensuring equitable education and eliminating disparities among vulnerable groups (3 specific goals); building social capital for education (3 specific goals) ;equipping learners with necessary skills and knowledge (4 specific goals); providing safe, nonviolent, inclusive and effective learning environments for all (4 specific goals); and raising awareness on climate change and disaster risk reduction (3 specific goals).

KH2161 also offers ministries, branches and localities comprehensive solutions and appropriate roadmap; while assigning responsibility to all departments and institutes under the Ministry of Education and Training to implement the plan.

Based on KH2161, the Ministry of Education and Training decided to establish the National Steering Committee (NSC), which is headed by the Deputy Minister and assisted by the Secretariat, to implement SDG4. The NSC held a national conference to disseminate KH2161 to 63 departments of education and training, and requesting all provinces and cities under the Central Government to develop suitable implementation plans to local regions. In the meantime, the NSC also direct, guide and examine the integration of SDG4 objectives into annual development goals for education and training; and review, evaluate and develop statistical criteria in order to collect information for inspection and supervision. The NSC will be monitored, supervised and periodically reported to the Minister and Government by all departments and institutes under the Joint Chiefs of Staff.

\subsection{Difficulties and challenges in implementation plan}

After a year of implementing KH2161, in June, 2018 in Da Nang, the Ministry of Education and Training collaborated with the UNICEF and other international partners to organize the 2018 GAWE and disseminate action plan of implementing sustainable development goals for education, which still has some difficulties and challenges:

_After 1 year, only 29/63 provinces and cities have sent reports of SDG4 implementation plan (including 9 localities where their chairman of the People's Committee directly signed the plan for approval).

_ Limited financial resources, including federal budget and funding, despite the constraints of social mobilization.

_ Awareness transformation of all inadequate sectors. 


\section{International Journal of Social Science and Economic Research}

ISSN: $2455-8834$

Volume:05, Issue:12 "December 2020"

_ Many targets are still at low level. Thus, it requires some drastic solution to achieve 2025 goal, such as:

- Rising proportion of enrollment in secondary education (children aged 11-14) from current $91 \%$ to $97 \%$; reducing proportion of children that have not enrolled in school (TENNT), in which primary school-aged children from current $2.6 \%$ to $1.0 \%$, and middle school-aged children from current $7.7 \%$ to $6.0 \%$ in 2015 (Goal 4.1).

$\circ$ Ensuring development of early childhood education from $16 \%$ to $35 \%$; and increasing proportion of quality pre-school experience from $90 \%$ to $98 \%$ in 2025 (Goal 4.2).

$\circ$ Increasing proportion of standardized school facilities, which have hygienic toilets and safe drinking water from $1 \%$ to $2 \%$ per year; and which are child, disability and gender sensitive from $47 \%$ to $55 \%$ in 2015 (Goal 4.a).

- Decreasing number of students/ class ratio, number of students/teacher ratio; and ensuring number of teachers/class ratio based on the new class size are challenging targets (Goal 4.c). Currently, the average class size in Vietnam is in high level, which can be 2-2.5 time higher than developed countries. Reducing this ratio requires a huge financial investment for education facilities and working location. Therefore, this problem is impossible to be resolved by only Department of Education and Training, but requires a serious solution from the Party and the Government.

_ Some of the monitoring and supervising indexes have not been specified and thus limit the accountability in management. In which, some compulsory indexes are evaluated, such as:rate of children who achieve minimum proficiency levels in reading and mathematics; rate of children who have positive experiences; rate of youth and adults who have technical and vocational skills; rate of students who understand about global citizenship and sustainable development; rate of schools meeting essential conditions for people with disabilities; and rate of students who are involved in bullying, humiliation, school violence, harassment, or sexual abuse...

_ Difficulties and obstacles of transformation in mindset and management methods are still remained. In Ha Noi, Lesley Miller, a UNICEF Deputy Representative, states that in order to achieve SDG4 in education, Vietnam should not follow its familiar former way; and discusses 3 solutions (all relating to accountability for a leave-no-one-behind education):

- First, improving data collection and practical evidence is one of the prerequisites for monitoring the implementing progress. It is important to know and overcome our weaknesses by ensuring detailed data availability, not only in universal access to quality 


\section{International Journal of Social Science and Economic Research}

ISSN: $2455-8834$

Volume:05, Issue:12 "December 2020"

education, but also in equitable quality of teaching and learning, especially at the provincial level.

- Second, policies, planning processes and budget estimates should be based on authentic evidence from data collection and analysis. It is necessary to integrate the relevant SDG4 indicators systematically, and provide methods of resource allocation to all areas where it is most needed, including schools.

- Third, cross-relationship between ministries and localities should be considered an important element of the SDG4 agenda in implementation, data collection and even accountability. The sources of data implementation need to have a close combination of ministries and localities.

\subsection{Recommendation of implementation:}

Increasing accountability level of implementing KH216 mainly depends on universal access to quality education at all levels. It is necessary to gather enough data to evaluate level of accessibility to practical education by different social class in all regions; on the other hand, targeting to make education more accessible and leave no one behind.

_ First of all, awareness on integration, equity and equality need to be changed. Integration is ensuring full participation and no separation from all parties, which is evaluated by some measurement tools for accountability. Equity and equality are two sensitive areas when developing policies. Ensuring equity may not create equality; therefore, it is necessary to carefully consider when it comes to fairness and when it is about equality. Additional, the integration into all policies, all levels of education, and responsibilities from all ministries, sectors and localities is needed to implement inclusive and equitable quality education. That means the Government needs to have appropriate direction to mobilize overall strength of the whole society and the political system.

_We have to admit the current limitations in gathering management information of education sector as well as the discipline of reporting at all levels. Even data on federal budget expenditures of all sectors are subject to annual delays. With a huge amount of necessary information for implementing SDG4 results, this situation would be impossible. Decentralized management of budgeting and human resources of the education sector is very fragmented because of shortcomings. It is necessary to propose the Government forimplementinga decentralized management system on education in order to achieve higher effectiveness and efficiency. 


\section{International Journal of Social Science and Economic Research}

ISSN: $2455-8834$

Volume:05, Issue:12 "December 2020"

_ In parallel with improving the implementation of a decentralized management system, the NSC has to assign, direct and ensure intervention at all levels and sectors in reporting, providing sufficient information for the monitoring, evaluation and interpretation of outcomes. The NSC need to specifically assignMinistry of Planning and Investment (General Statistics Office), Ministry of Finance, Ministry of Labour - Invalids and Social Affairs, all other relevant branches and localities to provide sufficient information for them to make final decision.

_ Among 45 monitoring and supervising indicators of KH2161, some were shown in the analysis, the rest were either quantified or lacked of channels used to collect the information. If the system is not complete, there will not be enough "materials" for evaluating or implementing accountability. The Ministry of Education and Training has to define qualitative indicators and establish information and reporting channels for all indicators as soon as possible.

_ The Ministry of Education and Training should review all software of management information systems (Education Management Information System - EMIS, Eradication of Illiteracy Information System, Project Management Information System - PMIS, Project Planning Software - VANPRO ...); implement the principle of former outcomes (in which taking advantage of user habits and skills); expand criteria and channels of data collection and avoid making too many changes. Also, the application of information technology is important to ensure savings and effectiveness.

_ The idea of TENNT from the United Nations need to be applied in a systematic and comprehensive way to all levels, thus considering it as an essential solution to ensure that everybody has equal access to all levels of education, especially vulnerable groups, and making sure that "no one is left behind". The responsibility of collecting information on TENNT (answering the question "What is TENNT?") and analyzing barriers (answering the question "Why can't they go to school?") must be determined from educational basis and is managed directly by the executive committee. The statistical analysis and reporting system should be set up throughout the Department, Division and Ministry of Education and Training. Thence, the Ministry will analyze and create policy based on synthesized data (answering the question "How to help them enroll in school?").

_ Proposing the Government for implementing a re-planning policy system to remove barriers that helps increase enrolment rates in schools. Old policies need to be reviewed and updated on the basis of limiting unreasonable contents and reinforcing strengths to minimize ineffective aspects. Beside financial assistance policy, it is necessary to pay attention to promulgate social policy in order to eliminate barriers for children with disability, emotional disturbance, centuriesold customs or influence from parents' immigration... 
International Journal of Social Science and Economic Research

ISSN: 2455-8834

Volume:05, Issue:12 "December 2020"

_ Directing of planning and budgeting on education field based on strategic planning and resultsbased management. Educational plans must be created based on accurate assessment of TENNT, thus determining priority objectives and evaluating conditions of human resources, finance, facilities for implementation. In the same time of approaching quality and management, social impact assessment of equitable education should be used as a measure of the plan. The "leaveno-one-behind education" criteria must be considered an effective measure of the whole process(before, during and after the implementation); and promulgated throughout the Department, Division and Ministry of Education and Training.

\section{References}

[1] TheMinistry of Education and Training (2017), Decision No. 2161/QĐ-BGDĐT on 26/6/2017 of publishing" The Implementation of Sustainable Development Goal for Education by 2025 and Orientation to 2030", Ha Noi.

[2] TheMinistry of Education and Training (2018), “Action Plan of Implementing Sustainable Development Goal for Education (SDG4), Conference report, Da Nang.

[3] The Government of the Socialist Republic of Vietnam (2012), "Implementation of Sustainable Development Goal", National report of the United Nations Conference on Sustainable Development (RIO+20), Rio de Janeiro, Brazil.

[4] Lesley Miller, UNICEF Deputy Representative of Vietnam (2018), "Opening Statements for Global Action Week for Education and Implementation of Sustainable Development Goal for Education", Da Nang.

[5] The Prime Minister (2015), "Decision No. 622/QĐ-TTg on 10/5/2017 of National Implementation on the 2030 Agenda for Sustainable Development”, Ha Noi.

[6] UNESCO, UNICEF, The World Bank, UNDP, UN Women và UNHCR (5/2015), "Incheon Declaration of Inclusive and Equitable Quality Educationand Promote Lifelong Learning Opportunities for All", Incheon (Korea).

[7] Le Khanh Tuan (2019), “Accountability for a "Leave-No-One-Behind Education”, Education magazine, Volume 447, Ha Noi. 